\title{
THE ROLE OF SCIENCE AND ENGINEERING IN MITIGATING NATURAL HAZARDS
}

\author{
Frank Press *
}

\section{BULLETIN EDITOR'S NOTE}

This keynote address delivered to the Eighth World Conference on Earthquake Engineering is reported here with permission. It is a thoughtful and stimulating contribution and deserves the careful attention of readers.

\begin{abstract}
Dr Penzien, President Hudson, President Agbabian, delegates, fellow scientists and engineers. This is the second keynote address in San Francisco in a week. The first dealt with a political approach to assure the wellbeing and security of people. This one has the same goal - using the tools of science and engineering. And both are needed if we are to address many of the global problems that we all face. It is a pleasure and an honour for me to participate in the Eighth World Conference on Earthquake Engineering for several reasons. The study of earthquakes is my own profession, and it is a great pleasure to renew the relationships I've had over the years with so many colleagues.
\end{abstract}

This gathering of some 1500 leading researchers and practitioners from 50 countries is a signal event, with a superb programme which gives evidence of the tremendous progress in this key field, progress that will lend impetus to a worldwide attack on the earthquake problem. And most important there is no higher calling for a scientist and engineer than to use his talents on behalf of his fellow man. Perusing the programme, one cannot but be impressed by the remarkable progress of recent years with new theoretical approaches, new data, and new kinds of experiments. And it is indeed heartening to see so many young people together with some of us who've been around for a while in this vigorous, renewing field.

I would like to organise my remarks this morning around four topics: some generalisations about natural hazards, the role of scientists and engineers in hazard mitigation, the role of governments. And I would like to conclude with a proposal for your consideration.

A philosopher once said man lives by geological consent subject to change without notice. That one sentence

* President, National Academy of Sciences, USA. encompasses much of the story of life on earth. Our planet is unique in its ability to give rise to life. It's not so big as to keep by gravity a massive, crushing atmosphere, and it's not so small as to lose its atmosphere into space. It's not too far from the sun as to be cold and uninhabitable, nor is it too near. And that distance is critical by perhaps only 10 or 15 million miles. It has an internal engine fuelled by radioactivity that produced the continents, the oceans, the atmosphere, and minerals, but also produces earthquakes and volcanic eruptions. It has an external engine fuelled by the sun that spreads warmth, produces rain, energy for life, but also hurricanes, floods, typhoons, tornados. And finally it allowed for the evolution of man, conqueror of nature, provider of food and shelter, but also destroyer, inventor of tools of destruction rivalling nature. Earth is a uniquely hospitable place compared with our neighbours Venus and Mars.

But hazards come with the territory. They are rare, low probability events with consequences that are large in terms of destruction - which leads me to my first generalisation. The class of hazards characterised by low probability of occurrence and high consequences presents a difficult public policy problem: how to sustain public interest and involvement; how to attract adequate government resources for mitigation programmes? It's easy to understand how a country with a recent severe catastrophe such as Tokyo in 1923 or Tangshan in 1976 , can become concerned and organise national programmes. But it is the height of a civilised society to anticipate and control rather than to react only after a disaster. My second generalisation: earthquakes are a special category of hazards in that most human losses are due to failure of human-made structures - buildings, dams, lifelines, and so on. Therefore, in principle, with sufficient resources for research, development, education, followed by necessary investments in hazard reduction, earthquakes 
are a hazard that are within our power to respond to. We can reduce their threat over time as much as we want to. We can learn where not to build and how to build so that failure of structures will not occur. The third generalisation: a comprehensive programme of hazard reduction includes prediction, hazard reduction, in different ways for different kinds of hazards and in different ways for different countries. Let me give you an example: hurricanes. The prediction of hurricanes in many countries is at a high stage of accuracy and prediction of hurricanes saves lives. The warning is sufficient to evacuate populations from low lands and to take the necessary precautions. Hazard reduction in the case of hurricanes beyond prediction consists of instituting appropriate regulations for construction, sensible insurance policies which provide disincentives for construction in flood plains and low coastal areas, education and so on. In this way hazard reduction can reduce economic loss. Prediction of hurricanes can certainly save lives.

In the case of earthquakes, prediction is uncertain. It may only be achieved partially for certain classes of faults. It may never be achieved. Therefore, hazard reduction is key to saving lives and reducing economic loss. Prediction and hazard reduction complement each other in different ways for different kinds of hazards. And there are, of course, country differences. A typhoon in a country with poor communications and poor transportation might be predictable using global satellite means and other techniques but it is still deadly under today's circumstances. Thus hazards vary in man's ability to predict, to control, to respond to. They vary by hazard, and by country. Earthquakes represent an example of a hazard that may not be liable to prediction or control in the near term, but whose consequences can nevertheless greatly be reduced.

Let me say something about the role of scientists and engineers, and social scientists as well. The tradition of science goes back, of course, to ancient times when the fear of nature could only be dispelled by explaining nature's catastrophes. In the early days, of course, they were explained through religious myths, through astrology. And then with the advance of science came an understanding of natural phenomena, which assured people, and led to the beginnings of mitigation programmes. Progress in both science and technology brings us to tbe present day and our ability to intervene and reduce hazards. The role of scientists and engineers are complementary, they are mutually supportive as this conference shows. I am impressed at the progress since my own times as a contributor to this field, the progress manifest by scientists and engineers working together as partners, actually crossing over fields as well. Today there are scientists predicting ground motions from realistic models of faults, ground motions of the kind that are useful to engineers, taking into account transmission paths, rock types, typography. Engineers are refining magnitude scales that were originally developed by scientists. Scientists and engineers are jointly developing different kinds of risk assessment techniques. There is a blurring of fields and this is indeed healthy. This is not to minimise the distinctive contributions of the different professions scientists studying the nature of faulting and their possible contributions to the prediction of earthquakes; engineers, of course, in their traditional important work in the design of earthquake resistant structures; and social scientists pointing up the social and economic consequences of replacing low cost housing and commercial space which are also hazards at the same time.

A major problem for scientists and engineers, especially in the field of hazard mitigation, is to separate their role as professionals making analyses, listing options, from their political roles as citizens advocating partisan solutions. And here, I suppose, each of us has to make his own decision. I believe that we can indeed separate hazard assessment, which is essentially a technical, professional activity from hazard management, which is a political role of governments. With assessment, we evaluate risks, we analyse procedures for mitigating hazards, and we do this as professionals. This process educates the public and leads, hopefully, to informed decisions by government officials who have the responsibility for hazard management as a proper part of the political process.

Let me expand on the appropriate role for professionals in this highly charged field, for I believe the subject needs intensive discussion. There is a perception that scientists and engineers receive public funds without accounting to the public by way of explanation, by way of progress reports, the results of public support. I think this is a particular problem in your field because of the potential for hysteria, the severe human and economic consequences of a disaster, the repression of reality in people's minds to avoid thinking about the consequences of earthquakes. I believe therefore that it is particularly important for scientists and engineers working in earthquake research to be concerned with public education - by way of lectures, articles, films, visits to communities and schools. And, of course, the key job of professionals in the earthquake field is to lay out programmes appropriate to each country, involving assessment of risks, construction codes and standards, land use, criteria for the identification of safe and unsafe structures, the maintenance of lifelines during disasters and after disasters, emergency services, public education and training. Our knowledge is imperfect and therefore it is part of our job to propose a research and development programme involving all aspects of the field - ground motion, soil mechanics, structural dynamics, 
the design of structures, the social and economic aspects, and the training of technical manpower to provide adequate back-up for this important endeavour. However, if governments do not assume their proper role of hazard management after being provided the assessment of professionals, hazard mitigation will not occur.

There are three factors which determine the destructiveness of an earthquake - its magnitude, its distance from a population centre, and the degree of preparedness. A country with poor preparedness will suffer more than one with good preparedness. Good government management is the key factor in preparedness, and therefore government performance is a major controllable factor influencing the impact of a disaster. With all of the possibilities for reducing the hazards of earthquakes mentioned earlier - the codes, the land-use procedures, the emergency services, the public training, the research and development programmes, the training of professionals, why do some countries have inadequate preparedness programmes? of course, there are countries that are very poor, with meagre technical and financial resources, and one can understand why they would lag behind. But it is difficult to understand the shortsightedness of some advanced nations.

When I was serving in government, an official in the Office of Management and Budget once posed the following to me: "You scientists always want more. How do you know when you've had enough?" I answered in terms that he could understand. First, in financial terms involving return on research and development investments, then in human terms involving the obligation of governments to provide for the security of its people in terms of its economic growth. I also answered in political terms. I said: "How would you like to go down in history, following a major catastrophe, as the official responsible for a lack of preparedness?" Those of you who deal with government officials hear responses similar to the ones I heard: "Earthquakes will not happen during my term in government, and I have more immediate budgetary needs to take care of." Or: "A cost/benefit analysis shows that only 500 people have died in this century from earthquakes in the United States. How can you justify such a large investment?" These are shortsighted views and I think all of you know the answers to such questions.

I believe that concern about the public welfare is a primary role of a modern government, and in this sense natural hazard mitigation deserves attention with high priority. It is interesting to recall that in ancient China, dynasties fell after a major earthquake - as if the Emperor should have protected his people against such a catastrophe. I suppose the modern analogue to that is the political process and the reaction of a citizenry that sees inadequate attention to hazard reduction. I believe that a modern government should not wait for a Tokyo of 1923 or a Tangshan of 1976 before it commits adequate resources. Certainly governments should support adequate research and development programmes. They are needed, and can return enormous benefits. $R$ \& $D$ is really not terribly expensive in the scheme of things. The same can be said for public education and the preparation of construction codes. It is more difficult to deal with the larger financial resources, both public and private, that are needed with the implementation of construction codes or the replacement of unsafe buildings with new buildings that meet modern codes. This should be part of decision-making through the political process. I believe an educated citizenry will insist on an adequate response from their governments. History will judge governments not only by their attention to health, education and economic growth but also by preparing their countries in advance of natural disasters.

I would like to make a proposal to you on the occasion of this Eighth World Conference. It is a proposal to establish an International Decade of Hazard Reduction (IDHR). By way of background, let me remind you that natural hazards know no national boundaries except the earth itself, that there is already a history of cooperation in earthquake engineering between nations, some examples of which are being reported on at this very conference. Cooperation between scientists and engineers is international by long tradition. The large number of scientists from so many different countries present today gives evidence to that. To counter some dangerous trends in competition between nations, worldwide cooperation on behalf of people everywhere would be an important symbol.

An IDHR would exploit many of the scientific and engineering advances of recent years. Research on natural hazards, particularly earthquake hazards, is moving to a new era characterised by theoretical advances, large-scale field experiments, expensive experimental testing facilities, use of supercomputers, access to global monitoring and communication facilities. At the same time hazards research in many countries is funded below the level that is really needed to fully utilise these new opportunities.

In view of these observations, I believe there is great need, and much support can be found, to establish an International Decade of Hazard Reduction. This special initiative would see all nations joining forces to reduce the consequences of natural hazards. The planning could start within a year or two, with the preparation of national plans. The implementation could take place in a few years. Perhaps it would be appropriate for the final decade of this century. What better way to start the new millenium than a world better organised to reduce suffe ing.

What would be some of the features of IDHR? Earthquake hazards would be a major element of such a programme. 
The earthquake professionals are well organised, witness this meeting. The field is positioned for making rapid advances, given the impetus of a dedicated, coordinated, international effort. For example, an international supercomputer facility dedicated to natural hazard research might be established. Machines with billions of floating point operations per second would be part available by that time. With this level of computing power, one can think of expert systems for the design of structures using realistic non-linear models. One can think of calculations of ground motion based on realistic earthquake fault models and wave propagation models. One can envisage international teams undertaking the regionalisation of risk. Many parts of the world that are particularly prone to earthquakes have not had the advantages of a risk assessment for their region.

National goals for participation in the international decade could be a major spur to country action. Think of what the International Geophysical Year some 25 years ago did for the field of geophysics in this country and your countries. As a significant bonus, an international programme can improve the infrastructure for hazard mitigation in the developing countries where the problems are so severe, the dangers are so great, and the ability to respond is so poor. Experimental facilities that require high capital outlays and that contribute so much to our understanding of how to design and build buildings can be done on an international basis, perhaps using the CERN models developed for particle physics. Costs would be shared and access would be provided to all countries. Another component might be a global strong motion network with standardised instruments. Another feature might be a plan for international cooperation in providing post-disaster relief.

The world is more vulnerable to cataclysms today than ever before because of the growing population, the concentration of population, the fragility of lifelines, the interdependence of people. Our knowledge of the effects of great cataclysms is growing. For example, there is growing concern about a new source of danger - resurgent calderas. These are huge volcanic collapse features which combine the destructiveness of earthquakes as well as huge volcanic eruptions. Imagine events that are 1000 times more powerful than the eruption of Mount St Helens, which itself caused damage of over $a$ billion and $a$ half dollars. Some resurgent calderas are showing renewed activity in the form of surface doming, earthquake swarms and evidence of magma accumulating a few kilometres beneath the surface. The geologic record tells us that the occurrence rate might be about ten per million years. The destructiveness of some resurgent calderas can be measured in millions of square miles of agricultural land wiped out by the ash deposits, the lofting of fine ash and the sulphur products into high atmosphere, blotting out the sun for perhaps weeks at a time, producing worldwide agricultural losses. An IDHR would include studies of resurgent calderas, earthquakes, cometary impacts, storms and other destructive natural phenomena.

Some concluding thoughts. By any measure, civilisation has made much progress in this millenium. I think the world is better off today than it was 100 years ago, certainly better off than it was 500 years ago. If you have any doubts, as some do, think in terms of life expectancies and how they have improved, of the elimination of famine, the elimination of epidemics, and the remarkable economic progress. Science and technology has been the major factor responsible for the improved state of humankind. Yet much remains to be done. We are haunted by the spectre of natural hazards, with immense consequences, because of concentrated populations, frailty of modern social institutions, and the other factors that I have mentioned. Some major earthquakes are expected in the next few years. Indeed, they may be "overdue"! Can we minimise their destructiveness? Most of you will agree with me that we will have the technical means to do so in the year ahead.

Indeed, humankind has the technical means to achieve great things this next millenium: we can provide an adequate food supply, conquer disease once and for all, provide global education, extend economic progress, and greatly reduce the risk of natural hazards. Most important - we can eliminate war so that the worst hazard of all - nuclear war - is no longer a threat. I believe we can and must progress in this manner. Perhaps this is our last opportunity to do so. I believe that the involvement of dedicated scientists and engineers, such as those gathered in this room today, is the key to achieving these essential global goals. 